\title{
Organ-Specific Recurrence or Metastatic Pattern of Breast Cancer according to Biological Subtypes and Clinical Characteristics
}

\author{
Jaeyoon Kim, M.D., Yujin Lee, M.D., Taeyong Yoo, M.D., Jungbin Kim, M.D., Jonghee Hyun, M.D., \\ Inseok Park, M.D., Hyunjin Cho, M.D., Keunho Yang, M.D., Ph.D., Byungno Bae, M.D., Ph.D., \\ Kihwan Kim, M.D., Ph.D., Kyeongmee Park', M.D., Ph.D., Geumhee Gwak, M.D., Ph.D. \\ Department of Surgery, ${ }^{1}$ Department of Pathology, Sanggye Paik Hospital, Inje University College of Medicine, Seoul, Korea
}

Purpose: We aimed to investigate organ-specific recurrence or the metastatic pattern of breast cancer according to biological subtypes and clinical characteristics. Methods: We retrospectively analyzed the medical records of 168 patients with recurrent breast cancer who were diagnosed between January 1, 2000 and April 30, 2017. Four biological subtypes were classified according to estrogen receptor (ER), progesterone receptor (PR), human epidermal growth factor receptor 2 (HER2), and Ki-67 expression: luminal A, luminal B, HER2-enriched, and triple negative breast cancer (TNBC). To analyze recurrence patterns according to biological subtypes, we accessed clinical variables including age at diagnosis, TNM stage, type of surgery in the breast and axilla, histologic grade, nuclear grade, lymphatic, vascular, and neural invasion, Ki-67 expression and recurrence to distant organs. Results: The biological subtypes of recurrent breast cancer comprised the following luminal $A(n=33,19.6 \%)$, luminal $B(n=95,56.5 \%)$, HER2 enriched $(n=19,11.3 \%)$, and TNBC $(n=21,12.5 \%)$. Luminal A (7.7\%) and B (6.5\%) subtypes were associated with the increased rate of local recurrence compared to HER2-enriched (2.4\%) and TNBC subtypes (1.8\%) $(p=0.005)$. The bone (53.6\%) was the most common metastatic organ, followed by the lung $(34.5 \%)$, liver $(29.8 \%)$, brain $(17.9 \%)$, and other visceral organ (7.7\%). Bone metastasis was commonly observed in individuals with luminal B (63.2\%), HER2-enriched (57.9\%), and luminal A $(42.4 \%)$ subtypes $(p=0.005)$. Most liver metastases occur in individuals with luminal B $(40.0 \%)$ and HER2-enriched subtypes $(31.6 \%)$ $(p=0.002)$. Conclusion: Luminal B subtype was commonly observed in individuals with recurrent breast cancer, and the bone is the most common target organ for breast cancer metastasis, followed by the lungs and liver.

Key Words: Breast neoplasms, Neoplasm metastasis, Organ specificity, Recurrence

\section{INTRODUCTION}

Breast cancer is a clinically and biologically heterogenous disease $[1,2]$. Recurrent breast cancer is the reappearance of breast cancer in different organs, including the breast. Recent findings have indicated that immunohistochemical protein expression profiles are surrogates for intrinsic gene-derived expression profiles defining molecular breast cancer subtypes $[3,4]$. The intrinsic molecular subtypes are distinguished according to the expression of genes involved in luminal epithelial differentiation (e.g., estrogen receptor [ER] and progesterone receptor $[\mathrm{PR}]$ genes), proliferation (e.g., Ki-67 gene), human epidermal growth factor receptor 2 (HER2) pathway $[5,6]$.

Metastatic spreading models describe the complex interplay of seed

Correspondence: Geumhee Gwak, M.D., Ph.D.

Department of Surgery, Sanggye Paik Hospital, Inje University College of

Medicine, 1342 Dongil-ro, Nowon-gu, Seoul 01757, Korea

Tel: +82-2-950-1017, Fax: +82-2-933-9389, E-mail: s2606@paik.ac.kr

Received: Oct 1, 2018 Revised: Oct 20, 2018 Accepted: Apr 13, 2019 and soil factors, including tumor invasion, circulation, extravasation, proliferation, angiogenesis, and the microenvironment of the target tissue [7,8]. The biological characteristics of the primary tumor are usually preserved in metastatic organ. The gene signatures of lung and bone metastases have been reported, and HER2 and ER expression status is associated with the increased risk of metastasis to specific sites [9-11]. ER-negative tumors are associated with early recurrence, and ER-positive tumors are correlated to persistent risk after 5 years [12]. Two large studies of triple negative breast cancer (TNBC) have reported that brain metastasis occurred in about $6 \%$ of patients with early-stage breast cancer $[9,13]$. According to a previous study, the rate of metastasis in the central nervous system is higher in individuals with ER-negative/HER2-positive tumors than in those with ER-/HER2positive tumors [11]. The bone was found to be a common metastatic sites in individuals with ER-positive tumors [14-16]. In this study, we aimed to investigate the clinical patterns of metastasis or relapse of breast cancer according to biological subtypes. 


\section{METHODS}

\section{Patients}

We retrospectively reviewed the medical records of 168 patients diagnosed with recurrent breast cancer among 1,118 patients with breast cancer who were diagnosed between January 2000 and April, 2017 in a single medical institution. No exclusion criteria were applied. We reviewed the clinical and pathologic data of the patients, which include age at diagnosis, TNM stage, type of surgery in the breast and axilla, histologic grade (HG), nuclear grade (NG), lymphatic invasion (LI), vascular invasion (VI), neural invasion (NI), expression patterns of ER, PR, HER2, and Ki-67, recurrence in distal sites, disease free survival (DFS), and overall survival (OS). The study was approved by Inje University Sanggye Paik Hospital Institutional Review Board (201710-009), and the need for informed consent was waived.

\section{Classification of the biological subtypes based on immunohistochemistry $(\mathrm{IHC})$ staining results}

The biological subtypes were classified into four categories according to the ER, PR, HER2, and Ki-67 expressions: luminal A, luminal B, HER2-enriched, and TNBC. We defined luminal A as ER- and/or PRpositive, HER2-negative, and Ki-67 <20\%, luminal B as ER- and/or PR-positive, and HER2-positive or Ki-67 $\geq 20 \%$, HER2-enriched as ER- and PR-negative, and HER2-positive, and TNBC as ER-, PR-, and HER2-negative.

\section{IHC staining for ER, PR, and Ki-67 in breast cancer}

ER NCL-1-ER-6F11 and PR NCL-L-PGR-312 liquid mouse monoclonal antibodies (Leica Microsystems Inc., Newcastle Upon Tyne, UK) diluted 1:80 with normal goat serum (diluted 1:5 with Tris-buffered saline) were used as the primary antibodies for the ER and PR assays, respectively. Goat anti-mouse peroxidase conjugated immunoglobulin was utilized. 3, 3'-Diaminobenzidine tetrahydrochloride (DAB) was the second antibody used as a chromogen. ER and PR were scored as $0,1+, 2+$, and $3+$ according to staining intensity related to the proportion of stained nuclei in 10 high-power fields [17]. IHC for Ki67 in breast cancer was performed with aminoethylcarbazole as the chromogen and the Vectastain Avidin-Biotin Complex Elite kit (Vector Laboratories, Burlingame, USA) using the avidin-biotin peroxidase complex method. The low proliferative group was identified based on a Ki-67 cut-off of $20 \%$, which was considered optimal after stratifying for luminal breast cancer in high-risk patients [18].

\section{IHC staining for HER2/neu in breast cancer}

Using the Dako Quick-Staining, binding of the primary antibody was detected and labelled using the Streptavidin-Biotin System (Dako, Carpinteria, USA) followed by the addition of DAB chromogen. Two pathologists scored each slide in a blinded fashion according to the manufacturer's recommended criteria. Intensity scores of 0 or $1+$ were assigned as negative expression, 3+ as positive expressions for HER2/ neu, and 2+ as equivocal, which was analyzed via silver-enhanced in situ hybridization (SISH) [17].

\section{SISH for HER2}

SISH for HER2 was performed according to the manufacturer's protocols for INFORM HER2 DNA and chromosome 17 probes using a Ventana Benchmark automated instrument (Ventana Medical Systems Inc., Tucson, USA). Assessment of HER2 gene amplification status was performed in a blinded manner according to guidelines of the American Society of Clinical Oncology/College of American Pathologists [19].

\section{Statistical analysis}

Age of the patient, time of diagnosis, time of recurrence, location of the first recurrence, site of recurrence (breast, bone, brain, liver, lungs, skin and other internal organs), stage, type of breast surgery, pathologic findings, and expression of ER, PR, HER2, and Ki-67 were analyzed according to biological subtypes using Medcalc version 18 (MedCalc Software, Ostend, Belgium). The characteristics of the patients and tumors were compared according to breast cancer subtypes using the chi-square test. The association between site of relapse and biological subtypes was assessed using the chi-square test. The probability distributions of DFS and OS were analyzed using the Kaplan-Meier method. Statistical analyses were two-sided, and $p$-values $<0.05$ were considered statistically significant. We defined OS as the time from initial diagnosis to death and DFS as the time from end of initial therapy to reappearance of breast cancer. 


\section{RESULTS}

Clinical and pathological characteristics of recurrent or metastatic breast cancer according to biological

\section{subtypes}

A total of 168 patients included in the study. The biological subtypes of recurrent breast cancer were as follows: luminal A ( $n=33$, 19.6\%), luminal B ( $\mathrm{n}=95,56.5 \%)$, HER2-enriched $(\mathrm{n}=19,11.3 \%)$, and TNBC $(\mathrm{n}=21,12.5 \%)$. The clinical and pathological characteristics and their distribution according to tumor subtypes are listed in Table 1. Female participants with luminal A subtypes were significantly younger than the participants with other subtypes $(p=0.025)$. Luminal B and HER2-enriched subtypes were associated with smaller tumors less than $2 \mathrm{~cm}$ compared with luminal A and TNBC subtypes ( $p=0.031)$. Nine patients $(27.3 \%)$ with luminal A, 52 (54.7\%) with luminal B, 13 (68.4\%) with HER2-enriched and 14 (66.7\%) with TNBC subtypes were lymph node (LN)-positive. The lowest rate of LN involvement was observed in patients with luminal A subtype $(p=0.006)$. The most common histological type was invasive ductal carcinoma (IDC), and a high incidence of lobular cancer was observed in individuals with luminal groups $(p=0.007)$. Breast-conserv- ing surgery (BCS) was more commonly performed in patients with luminal A subtypes (57.6\%), followed by luminal B (45.3\%), TNBC (42.9\%), HER2-enriched subtypes (36.8\%), However, the results was not statistically significant $(p=0.763)$.

\section{Organ-specific recurrence or metastatic pattern of breast cancer}

Luminal A (42.4\%) and HER2-enriched (21.1\%) subtypes were associated with the increased rate of local recurrence compared to luminal B (11.6\%) and TNBC subtypes (14.3\%) ( $p=0.005)$ (Table 2). The TNBC subtype was associated with the increased rate $(9.5 \%)$ of regional (axillary nodes) recurrence compared with luminal A (3.0\%), luminal B (4.2\%), and HER2-enriched subtypes (5.3\%) $(p=0.719)$. The incidence of systemic recurrences was lower in individuals with luminal A subtype (57.6\%) than in those with luminal B (88.4\%), HER2-enriched (78.9\%), and TNBC subtypes (85.7\%) which showed a similar incidence, and the difference was statistically significant $(p=0.001)$. The common recurrence sites were the bone in 90 (53.6\%), lungs in 58 (34.5\%), liver in 50 (29.8\%), breast in 32 (19.0\%), brain in 30 (17.9\%), other visceral organs in 13 (7.7\%), and axillary LN in 8 (4.8\%) patients, respectively. Bone metastasis was commonly observed in individuals

Table 1. Clinical and pathological characteristics of the patients

\begin{tabular}{|c|c|c|c|c|c|}
\hline Characteristic & $\begin{array}{c}\text { Luminal A } \\
\qquad(n=33) \\
\text { No. }(\%)\end{array}$ & $\begin{array}{l}\text { Luminal B } \\
\qquad(n=95) \\
\text { No. }(\%)\end{array}$ & $\begin{array}{l}\text { HER2-enriched } \\
\qquad \begin{array}{c}(n=19) \\
\text { No. }(\%)\end{array}\end{array}$ & $\begin{array}{l}\text { TNBC } \\
(n=21) \\
\text { No. }(\%)\end{array}$ & $p$-value \\
\hline Median age (yr) & 46 & 50 & 49 & 52 & 0.025 \\
\hline \multicolumn{6}{|l|}{ Tumor size (cm) } \\
\hline$\leq 2$ & $12(36.4)$ & $62(65.3)$ & $13(68.4)$ & $12(57.1)$ & \multirow[t]{3}{*}{0.031} \\
\hline$>2$ & $20(60.6)$ & $33(34.7)$ & $5(26.3)$ & $9(42.9)$ & \\
\hline Missing & $1(3.0)$ & 0 & $1(5.3)$ & 0 & \\
\hline \multicolumn{6}{|l|}{ Lymph node status } \\
\hline Negative & $24(72.7)$ & $43(45.3)$ & $6(31.6)$ & $7(33.3)$ & \multirow[t]{2}{*}{0.006} \\
\hline Positive & $9(27.3)$ & $52(54.7)$ & $13(68.4)$ & $14(66.7)$ & \\
\hline \multicolumn{6}{|l|}{ Histological type } \\
\hline IDC & $24(72.7)$ & $84(88.4)$ & $18(94.7)$ & $19(90.5)$ & \multirow[t]{4}{*}{0.007} \\
\hline ILC & $2(6.1)$ & $4(4.2)$ & 0 & 0 & \\
\hline DCIS & $7(21.2)$ & $3(3.2)$ & 0 & 0 & \\
\hline Other & 0 & $4(4.2)$ & $1(5.3)$ & $2(9.5)$ & \\
\hline \multicolumn{6}{|l|}{ Operative therapy } \\
\hline No & $1(3.0)$ & $5(5.2)$ & $2(10.6)$ & $1(4.7)$ & \multirow[t]{3}{*}{0.763} \\
\hline Breast conserving & $19(57.6)$ & $43(45.3)$ & $7(36.8)$ & $9(42.9)$ & \\
\hline Mastectomy & $13(39.4)$ & $47(49.5)$ & $10(52.6)$ & $11(52.4)$ & \\
\hline
\end{tabular}

HER2 = human epidermal growth factor receptor $2 ;$ TNBC = triple negative breast cancer; IDC= invasive ductal carcinoma; ILC=invasive lobular carcinoma; $\mathrm{DCIS}=$ ductal carcinoma in situ. 
with luminal B (63.2\%), HER2-enriched (57.9\%), and luminal A subtypes $(42.4 \%)(p=0.005)$. Liver metastases commonly occurred in individuals with luminal B (40.0\%) and HER2-enriched subtypes (31.6\%) $(p=0.002)$. However, the incidence of lung and brain metastases was similar in all subtypes. When we classified all patients according to the number of metastasis (single or multiple metastasis), 12 patients presented with single metastasis, which was comprised bone $(\mathrm{n}=7)$, lung $(\mathrm{n}=2)$, liver $(\mathrm{n}=2)$, and brain metastasis $(\mathrm{n}=1)$. In single bone metastasis, four patients presented with luminal B subtype, two with luminal A, and one with HER2-enriched subtype.

\section{Analysis of recurrence to distant sites according to biological subtypes}

In luminal A tumors, bone metastases (42.4\%) was most common, followed by lung (24.2\%), liver (15.2\%), brain (3.0\%), and other organ metastases (0.0\%). In luminal B tumors, bone metastases (63.2\%) were most common, followed by liver (40.0\%), lung (37.9\%), brain (21.1\%), and other organ metastases (8.4\%). In HER2-enriched tumors, bone metastases (57.9\%) were most common, followed by liver (31.6\%), lung
(31.6\%), brain (26.3\%), and other organ metastases (5.3\%). In TNBC tumors, lung metastases (38.1\%) were common, followed by bone (23.8\%), brain (19.0\%), liver (4.8\%), and other organ metastases (19.0\%) (Table 2).

\section{Association between disease stage and biological subtypes}

Based on the American Joint Committee on Cancer (AJCC) staging system at initial diagnosis of breast cancer and biological subtype, the highest percentage of stage III tumors was observed in individuals with HER2-enriched subtype, followed by luminal B, and TNBC subtypes. (Table 3). Ten (6.0\%) patients presented in stage 0 disease, 23 (14.9\%) with stage I disease, 51 (30.4\%) with stage II disease, 49 (29.1\%) with stage III disease, 33 (19.6\%) with stage IV disease. Stage 0 was observed only in individuals with luminal subtypes, luminal A $(n=6$, 18.2\%) and luminal B ( $\mathrm{n}=4,4.2 \%)$. The highest proportion of stage II tumors (33.4\%) was observed in individuals with TNBC subtype. Moreover, the highest percentage of stage III tumors (42.1\%) was noted in individuals with HER2-enriched subtype, and the highest per-

Table 2. Patterns of loco-regional recurrence and distant metastasis

\begin{tabular}{|c|c|c|c|c|c|c|}
\hline Recurrence/metastasis & $\begin{array}{c}\text { Total } \\
(n=168) \\
\text { No. }(\%)\end{array}$ & $\begin{array}{l}\text { Luminal A } \\
(n=33) \\
\text { No. }(\%)\end{array}$ & $\begin{array}{l}\text { Luminal B } \\
(n=95) \\
\text { No. }(\%)\end{array}$ & $\begin{array}{l}\text { HER2-enriched } \\
\qquad(n=19) \\
\text { No. }(\%)\end{array}$ & $\begin{array}{c}\text { TNBC } \\
(n=21) \\
\text { No. }(\%)\end{array}$ & $p$-value \\
\hline \multicolumn{7}{|c|}{ Local and systemic recurrence } \\
\hline Local & $32(19.0)$ & $14(42.4)$ & $11(11.6)$ & $4(21.1)$ & $3(14.3)$ & 0.005 \\
\hline Systemic & $136(81.0)$ & $19(57.6)$ & $84(88.4)$ & $15(78.9)$ & $18(85.7)$ & 0.001 \\
\hline Regional (Axillary nodes) & $8(4.8)$ & $1(3.0)$ & $4(4.2)$ & $1(5.3)$ & $2(9.5)$ & 0.719 \\
\hline \multicolumn{7}{|l|}{ Distant metastasis } \\
\hline Bone & $90(53.6)$ & $14(42.4)$ & $60(63.2)$ & $11(57.9)$ & $5(23.8)$ & 0.005 \\
\hline Liver & $50(29.8)$ & $5(15.2)$ & $38(40.0)$ & $6(31.6)$ & $1(4.8)$ & 0.002 \\
\hline Lungs & $58(34.5)$ & $8(24.2)$ & $36(37.9)$ & $6(31.6)$ & $8(38.1)$ & 0.530 \\
\hline Brain & $30(17.9)$ & $1(3.0)$ & $20(21.1)$ & $5(26.3)$ & $4(19.0)$ & 0.088 \\
\hline Other & $13(7.7)$ & 0 & $8(8.4)$ & $1(5.3)$ & $4(19.0)$ & 0.080 \\
\hline
\end{tabular}

HER2 = human epidermal growth factor receptor $2 ; \mathrm{TNBC}=$ triple negative breast cancer.

Table 3. AJCC staging based on biological subtypes

\begin{tabular}{|c|c|c|c|c|c|c|}
\hline Stage & $\begin{array}{c}\text { Total } \\
\text { No. (\%) }\end{array}$ & $\begin{array}{c}\text { Luminal A } \\
\text { No. (\%) }\end{array}$ & $\begin{array}{c}\text { Luminal B } \\
\text { No. (\%) }\end{array}$ & $\begin{array}{c}\text { HER2-enriched } \\
\text { No. (\%) }\end{array}$ & $\begin{array}{c}\text { TNBC } \\
\text { №. (\%) }\end{array}$ & $p$-value \\
\hline & $168(100)$ & $33(19.6)$ & $95(56.5)$ & $19(11.3)$ & $21(12.5)$ & 0.055 \\
\hline 0 & $10(6.0)$ & $6(18.1)$ & $4(4.2)$ & 0 & 0 & 0.527 \\
\hline 1 & 25 (14.9) & $5(15.2)$ & 11 (11.6) & $4(21.1)$ & $5(23.8)$ & 0.178 \\
\hline 2 & $51(30.4)$ & $13(39.4)$ & $27(28.4)$ & $4(21.1)$ & $7(33.4)$ & $<0.001$ \\
\hline 3 & 49 (29.1) & $5(15.2)$ & 31 (32.6) & $8(42.1)$ & $5(23.8)$ & $<0.001$ \\
\hline 4 & 33 (19.6) & $4(12.1)$ & $22(23.2)$ & $3(15.7)$ & $4(19.0)$ & $<0.001$ \\
\hline
\end{tabular}

HER2 = human epidermal growth factor receptor 2; TNBC = triple negative breast cancer; AJCC = American Joint Committee on Cancer 7th Edition. 
Table 4. Association between type of surgery and local recurrence

\begin{tabular}{|c|c|c|c|c|}
\hline \multirow[b]{2}{*}{ Variable } & \multirow{2}{*}{$\begin{array}{c}\text { Total } \\
\text { No. (\%) }\end{array}$} & \multicolumn{2}{|c|}{ Surgical method } & \multirow[b]{2}{*}{$p$-value } \\
\hline & & $\begin{array}{c}\text { BCS } \\
\text { No. (\%) }\end{array}$ & $\begin{array}{c}\text { Mastectomy } \\
\text { No. (\%) }\end{array}$ & \\
\hline Local recurrence & 168 & 78 & 81 & $<0.001$ \\
\hline Yes & $32(19.0)$ & $27(34.6)$ & $5(6.2)$ & \\
\hline No & $136(81.0)$ & $51(65.4)$ & $76(93.8)$ & \\
\hline
\end{tabular}

$\mathrm{BCS}=$ breast conserving surgery.

Table 5. Overall survival rate according to biological subtypes

\begin{tabular}{lccc}
\hline Biologic subtype & $\begin{array}{c}\text { Number of } \\
\text { events } \\
\text { No. }(\%)\end{array}$ & $\begin{array}{c}\text { Number censored } \\
\text { (OS rate) } \\
\text { No. (\%) }\end{array}$ & $\begin{array}{c}\text { Total sample } \\
\text { size } \\
\text { No. }\end{array}$ \\
\hline Luminal A & $8(24.24)$ & $25(75.76)$ & 33 \\
Luminal B & $51(53.68)$ & $44(46.32)$ & 95 \\
HER2-enriched & $13(68.42)$ & $6(31.58)$ & 19 \\
TNBC & $9(42.86)$ & $12(57.14)$ & 21 \\
Overall & $81(48.21)$ & $87(51.79)$ & 168 \\
\hline
\end{tabular}

$\mathrm{OS}=$ overall survival; $\mathrm{HER} 2=$ human epidermal growth factor receptor $2 ; \mathrm{TN}-$ $\mathrm{BC}=$ triple negative breast cancer; events = expiration by any cause.

Table 6. Survival outcome according to biologic subtypes

\begin{tabular}{lcrccc}
\hline Biologic subtype & $\begin{array}{c}\text { Mean } \\
\text { OS } \\
\text { (months) }\end{array}$ & SE $p=0.007$ & $\begin{array}{c}\text { Mean } \\
\text { DFS } \\
\text { (months) }\end{array}$ & SE $p=0.006$ \\
\hline Luminal A & 190.9 & 14.6 & 56.5 & 8.2 & \\
Luminal B & 117.7 & 9.9 & 37.0 & 3.8 & \\
HER2-enriched & 78.3 & 9.8 & 21.5 & 3.9 \\
TNBC & 107.4 & 15.6 & 32.7 & 8.3 \\
Overall & 135.1 & 8.0 & 38.6 & 3.0
\end{tabular}

$\mathrm{OS}=$ overall survival; $\mathrm{DFS}=$ disease free survival; $\mathrm{SE}=$ standard error; $\mathrm{HER} 2=$ human epidermal growth factor receptor 2 ; TNBC=triple negative breast cancer.

centage of stage IV tumors (23.2\%) was observed in individuals with luminal B subtype (Table 3).

\section{Association between type of surgery and local} recurrence

BCS was performed in 78 patients (46.4\%) and mastectomy in 81 patients (48.2\%). Nine patients (5.4\%) did not undergo surgery. The incidence of local recurrence was higher in the BCS group than mastectomy group (34.6\% vs. $6.2 \%)$ (Table 4$)(p<0.001)$.

\section{DFS and OS in recurrent or metastatic breast cancer}

Individuals with luminal A subtype had a higher OS (75.76\%) than those with TNBC (57.14\%), luminal B (46.32\%), and HER2-enriched
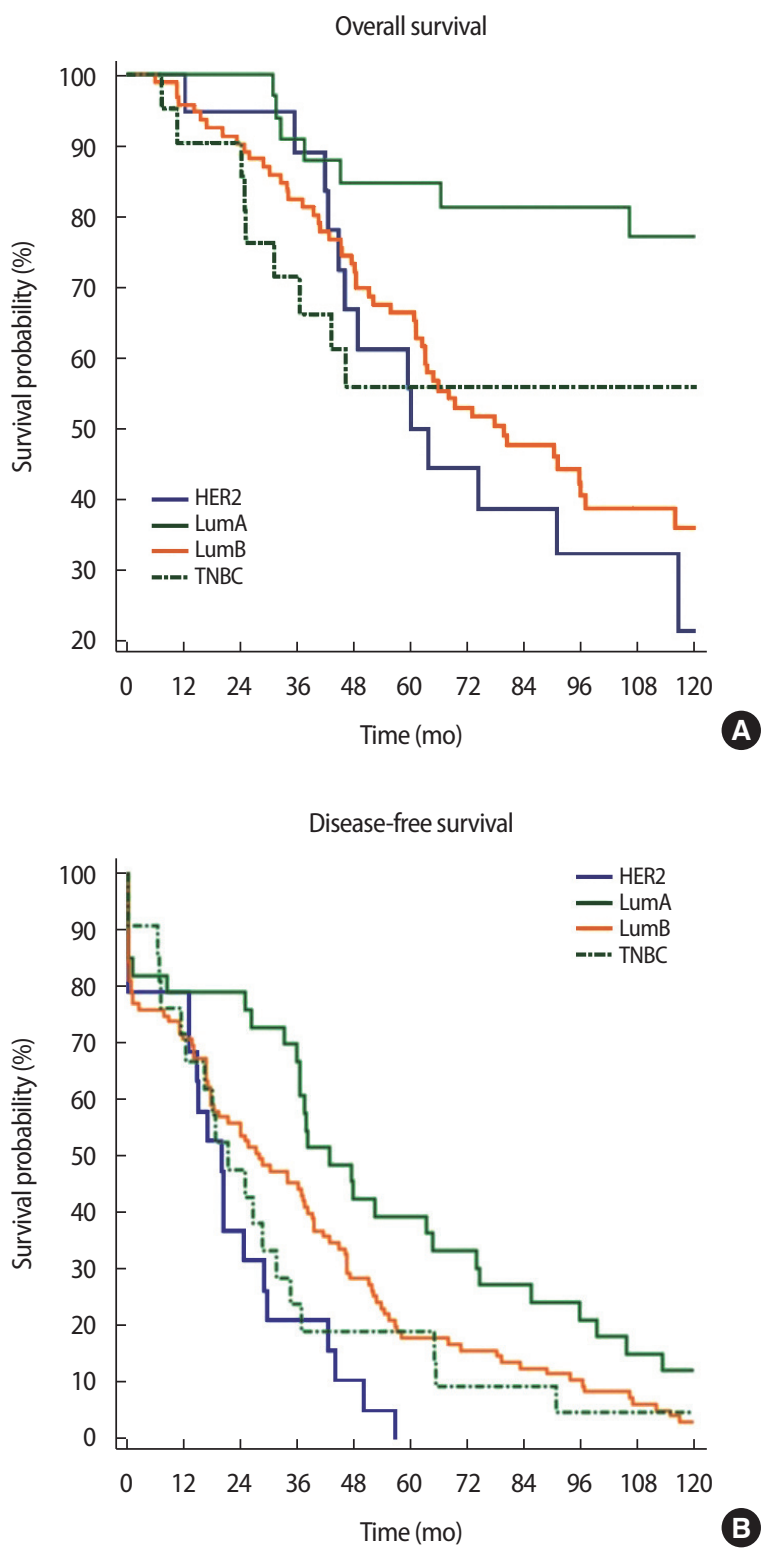

Figure 1. Kaplan-Meier survival curves according to biologic subtypes. (A) Overall survival $(p=0.007)$. (B) Disease-free survival $(p=0.006)$.

subtypes (31.58\%) $(p=0.007)$ (Table 5). Individuals with luminal A subtype had the highest mean DFS (56.5 months) $(p=0.006)$ (Table 6) (Figure 1). Among the different breast cancer subtypes, the OS and DFS rates were significantly different.

\section{DISCUSSION}

Previous studies have shown a significant difference in the recurrence patterns and rates of breast cancer according to breast cancer 
subtypes $[1,16,20-24]$. Luminal subtype account for $55 \%-80 \%$ of all breast cancers $[16,20,22]$. In our current study, luminal subtypes accounts for $76.2 \%$ of all patients with relapsed breast cancer and the number of patients with breast cancer as a whole. The risk of developing systemic metastasis was lowest in individuals with luminal A subtype $[16,20,22]$.

We observed that the survival curves of patients with relapsed breast cancer in this study were similar to the general pattern of the survival curves of all patients with breast cancer. Because this study only showed the survival curve of patients with recurrent breast cancer and previous cohort studies have revealed recurrence pattern of all patients with breast cancer, caution must be observed when to interpreting the results.

Luminal A tumors showed a statistically significant association with favorable DFS and OS compared to other subtypes, and our study showed such findings [1,16,20-24]. In numerous studies, HER2-enriched and TNBC subtypes had similar patterns and the highest locoregional recurrence rate [22,25]. Patients with ER-negative tumors were more likely to experience early relapse within the first 5 years with negligible risk of recurrence [20-24,26]. Conversely, ER-positive tumors are associated with the persistent risk of relapse even after 5 years [22].

Our study showed that the DFS of individuals with TNBC subtype was 60 months, and that of individuals with luminal A and B, HER2-enriched subtypes was $>120$ months. These results indicate that individuals with TNBC subtype experience recurrence within 5 years of the initial diagnosis. However, those with other subtypes will not present with recurrence even after 5 years of the initial diagnosis. In relation to this result, literature has shown that individuals with luminal subtypes had smooth peak during the initial years after diagnosis and remained at risk for the relapse even 10 years after diagnosis. This phenomenon is observed not only for relapse to distant organ but also for locoregional relapse and is indicative of individual follow-up and treatment strategy in patients with breast cancer in accordance with biological subtypes $[20,23,24]$.

The bone was found to be the most common metastatic site in patients with HR-positive breast cancer [16,20,23,27], and such finding was observed in our study. A large proportion of patients with HER2-enriched subtype present with liver metastasis. This result is consistent with that of previous studies showing that HER2-positive breast cancer is associated with liver metastasis $[20,27,28]$. The incidence of lung metastasis was similar in all subtypes. However, most patients presented with luminal B and TNBC subtypes [10,20,23,27, 28]. Numerous studies have shown that brain metastases were more likely to occur in patients with HER2-enriched and TNBC subtypes $[20,27,28]$, and brain metastasis in our study was commonly observed in HER2-enriched, luminal B, and TNBC subtypes. The incidence of recurrences in the regional or systemic LN is relatively low in luminal A subtype and this result is similar to those of previous studies [20,22,27,28].

In our current study, around two third of patients with luminal A and TNBC subtypes and less than half of patients with luminal B and HER2-enriched subtypes diagnosed at early stage (stage 0, I, or II) of breast cancer. Stage 0 was observed only in individuals with luminal subtypes but not in those with HER2-enriched and TNBC subtypes. The proportion of stage II tumors was the highest in individuals with TNBC subtype, and the proportion pf stage III tumors was the highest in individuals with HER2-enriched subtypes. Moreover, the proportion of stage IV tumors was the highest in individuals with luminal B subtype. This results indicate that luminal B and HER2-enriched subtypes are associated with poor prognosis [16,20,22].

Our study had several limitations. First, this study had a relatively small cohort ( $n=19$, HER2-enriched subtype and $n=21$, TNBC subtype) and this widens the confidence interval for all outcome estimates in a specific group, and lower associations were observed compared with those of other studies with larger cohorts [29]. Second, the present study is retrospective in nature and included all patients with recurrence or metastatic breast cancer at any stage (from stage 0 to stage 4), which indicate that all clinical outcomes were not well controlled, and this study only focused on actual phenomenon in clinical settings. Thus, the results of the present study cannot be generalized to all patients with breast cancer, and similarities with previous studies were not observed. However, recurrence or metastasis was more likely to occur, and based on the analysis of OS, DFS, TNM stage, and prognosis in all biological subtypes, this study was compared with previous studies as a control for analysis. Although there are limitations, the results may be useful in counseling individual patients about prognosis according to biological subtypes and individualized treatment.

The bone was the most common metastatic site in breast cancer. 
Luminal subtypes were correlated to initial bone metastasis. Liver metastasis commonly occurred in individuals with luminal B subtype. The incidence of lung metastasis was similar in all subtypes, and brain metastases commonly occurred in individuals with in HER2enriched subtype.

\section{CONFLICT OF INTEREST}

The authors declare that they have no competing interests.

\section{REFERENCES}

1. Prat A, Pineda E, Adamo B, Galvan P, Fernandez A, Gaba L, et al. Clinical implications of the intrinsic molecular subtypes of breast cancer. Breast 2015;24 Suppl 2:S26-35.

2. Prat A, Perou CM. Deconstructing the molecular portraits of breast cancer. Mol Oncol 2011;5:5-23.

3. Goldhirsch A, Winer EP, Coates AS, Gelber RD, Piccart-Gebhart M, Thurlimann B, et al. Personalizing the treatment of women with early breast cancer: highlights of the St Gallen International Expert Consensus on the Primary Therapy of Early Breast Cancer 2013. Ann Oncol 2013;24:2206-23.

4. Howlader N, Altekruse SF, Li CI, Chen VW, Clarke CA, Ries LA, et al. US incidence of breast cancer subtypes defined by joint hormone receptor and HER2 status. J Natl Cancer Inst 2014;106.

5. Althuis MD, Fergenbaum JH, Garcia-Closas M, Brinton LA, Madigan MP, Sherman ME. Etiology of hormone receptor-defined breast cancer: a systematic review of the literature. Cancer Epidemiol Biomarkers Prev 2004;13:1558-68.

6. Perou CM, Sorlie T, Eisen MB, van de Rijn M, Jeffrey SS, Rees CA, et al. Molecular portraits of human breast tumours. Nature 2000; 406:747-52

7. Norton L, Massague J. Is cancer a disease of self-seeding? Nat Med 2006;12:875-8.

8. Paget S. The distribution of secondary growths in cancer of the breast. 1889. Cancer Metastasis Rev 1989;8:98-101.

9. Lin NU, Bellon JR, Winer EP. CNS metastases in breast cancer. J Clin Oncol 2004;22:3608-17.

10. Minn AJ, Gupta GP, Siegel PM, Bos PD, Shu W, Giri DD, et al. Genes that mediate breast cancer metastasis to lung. Nature 2005;
436:518-24.

11. Clayton AJ, Danson S, Jolly S, Ryder WD, Burt PA, Stewart AL, et al. Incidence of cerebral metastases in patients treated with trastuzumab for metastatic breast cancer. Br J Cancer 2004;91:639-43.

12. Kennecke H, McArthur H, Olivotto IA, Speers C, Bajdik C, Chia SK, et al. Risk of early recurrence among postmenopausal women with estrogen receptor-positive early breast cancer treated with adjuvant tamoxifen. Cancer 2008;112:1437-44.

13. Miller KD, Weathers T, Haney LG, Timmerman R, Dickler M, Shen J, et al. Occult central nervous system involvement in patients with metastatic breast cancer: prevalence, predictive factors and impact on overall survival. Ann Oncol 2003;14:1072-7.

14. Alanko A, Heinonen E, Scheinin T, Tolppanen EM, Vihko R. Significance of estrogen and progesterone receptors, disease-free inter$\mathrm{val}$, and site of first metastasis on survival of breast cancer patients. Cancer 1985;56:1696-700.

15. Hess KR, Pusztai L, Buzdar AU, Hortobagyi GN. Estrogen receptors and distinct patterns of breast cancer relapse. Breast Cancer Res Treat 2003;78:105-18

16. Smid M, Wang Y, Zhang Y, Sieuwerts AM, Yu J, Klijn JG, et al. Subtypes of breast cancer show preferential site of relapse. Cancer Res 2008;68:3108-14.

17. Kim HS, Park I, Cho HJ, Gwak G, Yang K, Bae BN, et al. Analysis of the potent prognostic factors in luminal-type breast cancer. J Breast Cancer 2012;15:401-6.

18. Bustreo S, Osella-Abate S, Cassoni P, Donadio M, Airoldi M, Pedani F, et al. Optimal Ki67 cut-off for luminal breast cancer prognostic evaluation: a large case series study with a long-term follow-up. Breast Cancer Res Treat 2016;157:363-71.

19. Park K, Han S, Kim JY, Kim HJ, Kwon JE, Gwak G. Silver-enhanced in situ hybridization as an alternative to fluorescence in situ hybridization for assaying HER2 amplification in clinical breast cancer. J Breast Cancer 2011;14:276-82.

20. Kennecke H, Yerushalmi R, Woods R, Cheang MC, Voduc D, Speers CH, et al. Metastatic behavior of breast cancer subtypes. J Clin Oncol 2010;28:3271-7.

21. Saphner T, Tormey DC, Gray R. Annual hazard rates of recurrence for breast cancer after primary therapy. J Clin Oncol 1996;14:273846.

22. Ignatov A, Eggemann H, Burger E, Ignatov T. Patterns of breast can- 
cer relapse in accordance to biological subtype. J Cancer Res Clin Oncol 2018;144:1347-55.

23. Metzger-Filho O, Sun Z, Viale G, Price KN, Crivellari D, Snyder RD, et al. Patterns of Recurrence and outcome according to breast cancer subtypes in lymph node-negative disease: results from international breast cancer study group trials VIII and IX. J Clin Oncol 2013;31:3083-90.

24. Cossetti RJ, Tyldesley SK, Speers CH, Zheng Y, Gelmon KA. Comparison of breast cancer recurrence and outcome patterns between patients treated from 1986 to 1992 and from 2004 to 2008. J Clin Oncol 2015;33:65-73.

25. Voduc KD, Cheang MC, Tyldesley S, Gelmon K, Nielsen TO, Kennecke $H$. Breast cancer subtypes and the risk of local and regional relapse. J Clin Oncol 2010;28:1684-91.

26. Colleoni M, Sun Z, Price KN, Karlsson P, Forbes JF, Thurlimann B, et al. Annual hazard rates of recurrence for breast cancer during 24 years of follow-up: results from the international breast cancer study group trials I to V. J Clin Oncol 2016;34:927-35.

27. Gong Y, Liu YR, Ji P, Hu X, Shao ZM. Impact of molecular subtypes on metastatic breast cancer patients: a SEER population-based study. Sci Rep 2017;7:45411

28. Wu X, Baig A, Kasymjanova G, Kafi K, Holcroft C, Mekouar H, et al. Pattern of local recurrence and distant metastasis in breast cancer by molecular subtype. Cureus 2016;8:e924.

29. Nguyen PL, Taghian AG, Katz MS, Niemierko A, Abi Raad RF, Boon WL, et al. Breast cancer subtype approximated by estrogen receptor, progesterone receptor, and HER-2 is associated with local and distant recurrence after breast-conserving therapy. J Clin Oncol 2008;26:2373-8. 